\title{
SISTEM BASIS DATA PADA APLIKASI ANDROID KALKULASI BIAYA CETAK BUKU
}

\author{
Nofiandri Setyasmara ${ }^{a}$ \\ ${ }^{a}$ Politeknik Negeri Media Kreatif, Jakarta
}

INFORMASI ARTIKEL

Diterbitkan Online: 31 Juli 2021

\section{KATA KUNCI}

Kalkulasi Biaya Cetak, Aplikasi Android, MIT App Inventor, Online Database

\section{KORESPONDENSI}

Email: nofiandri@polimedia.ac.id

\section{A B S T R A C T}

Meningkatnya kebutuhan akan jasa cetakan, dan bervariasinya mesin cetak yang ada meningkatkan jumlah dan macam variabel yang harus dimasukkan ke dalam perhitungan biaya cetak. Di samping itu fluktuasi harga-harga barang secara umum juga memiliki dampak secara langsung pada perhitungan ongkos biaya cetak. Dengan demikian dibutuhkan suatu aplikasi yang dapat membantu melakukan perhitungan ongkos biaya cetak yang praktis dan dapat dibawa kemana-mana. Peneliti membuat rancang bangun aplikasi kalkulasi biaya cetak buku yang dapat digunakan pada perangkat bergerak (mobile device) berbasis Android. Data variabel yang digunakan pada aplikasi tersebut disimpan di dalam aplikasi dan bersifat permanen. Hasil pengujian run-time yaitu saat membuka halaman Daftar Harga/Tarif, baik pada aplikasi Pemutakhiran Data Harga/Tarif maupun aplikasi Kalkulasi Biaya Cetak dibutuhkan waktu lebih kurang 5 detik untuk menampilkan semua nominal harga dan tarif secara keseluruhan. Hal ini terjadi karena data harga dan tarif disimpan pada online database sehingga dibutuhkan untuk proses komunikasi data pada jaringan internet. Sedangkan hasil pengujian perhitungan menunjukkan adanya perbedaan antara hasil perhitungan manual dan hasil perhitungan aplikasi dengan prosentase kesalahan $0,4 \%$, dengan demikian tingkat akurasi perhitungan menggunakan aplikasi masih cukup tinggi yaitu 99,6\%. Adapun perbedaan ini terjadi karena adanya perbedaan mekanisme pembulatan angka desimal di belakang koma pada masing-masing perhitungan.

\section{PENDAHULUAN}

Perkembangan ekonomi kreatif di Indonesia semakin meningkat mengikuti perkembangan ekonomi kreatif di dunia. Pola hidup masyarakat telah mengalami evolusi dari masyarakat agraria, masyarakat industri, masyarakat informasi hingga pada evolusi terkini yaitu masyarakat kreatif (creative society). Ciri utama dari era masyarakat kreatif adalah pemberdayaan kekayaan intelektual dari masing-masing individu sebagai suatu aset yang dapat mendatangkan manfaat secara ekonomi. Menurut Kajian Industri Kreatif yang dilakukan oleh Departemen Perdagangan Republik Indonesia, industri kreatif adalah industri yang berasal dari pemanfaatan kreativitas, keterampilan, serta bakat individu untuk menciptakan kesejahteraan serta lapangan pekerjaan melalui penciptaan dan pemanfaatan daya kreasi dan daya cipta individu tersebut.

Industri kreatif, menurut Kajian Industri Kreatif Departemen Perdagangan Republik Indonesia, dapat dibagi menjadi beberapa subsektor yaitu: Periklanan, Arsitektur, Pasar barang seni, Kerajinan, Desain, Fesyen, Video, Film, Fotografi, Permainan interaktif, Musik, Seni Pertunjukan, Penerbitan dan Percetakan, Layanan Komputer dan Piranti Lunak, Televisi dan Radio, Riset dan Pengembangan. Sebagai salah satu subsektor industri kreatif, Penerbitan dan Percetakan termasuk industri yang berkembang cukup pesat. Permintaan jasa cetak on demand semakin meningkat, diiringi dengan ketersediaan berbagai macam peralatan cetak digital. Pesanan cetak on demand adalah pesanan cetak dengan variasi yang banyak dalam jumlah terbatas. 
Meningkatnya kebutuhan akan jasa cetakan, dan bervariasinya mesin cetak yang ada meningkatkan jumlah dan macam variabel yang harus dimasukkan ke dalam perhitungan biaya cetak. Di samping itu fluktuasi harga-harga barang secara umum juga memiliki dampak secara langsung pada perhitungan ongkos biaya cetak. Dengan demikian dibutuhkan suatu aplikasi yang dapat membantu melakukan perhitungan ongkos biaya cetak yang praktis dan dapat dibawa kemana-mana.

Penelitian tentang pengembangan aplikasi kalkulasi biaya cetak buku telah dilakukan oleh Nofiandri dan Sutiyo pada tahun 2014, yaitu perancangan dan pembuatan aplikasi kalkulasi biaya cetak buku yang dapat digunakan pada perangkat bergerak (mobile device) berbasis Android (Setyasmara, 2014). Aplikasi yang dihasilkan mampu melakukan perhitungan dengan akurasi mencapai 99,45\% dibandingkan dengan perhitungan manual. Variabel-variabel harga yang digunakan pada aplikasi tersebut disimpan di dalam aplikasi dan bersifat permanen.

Pada kondisi praktis harga bahan cetak dan jasa bersifat dinamis, maka diperlukan adanya suatu sistem basis data terpusat yang dapat memudahkan proses pemutakhiran data pada aplikasi kalkulasi biaya cetak buku khususnya untuk variabel-variabel harga bahan cetak dan jasa cetak. Dengan adanya sistem pemutakhiran data secara online (dalam jaringan) diharapkan dapat meningkatkan efektifitas hasil perhitungan dari aplikasi kalkulasi biaya cetak buku.

\section{TINJAUAN PUSTAKA}

\subsection{Mobile Platform Android}

Android adalah sistem operasi untuk mobile device yang awalnya dikembangkan oleh Android Inc. Perusahaan ini kemudian dibeli oleh Google pada tahun 2005. Android dibuat berdasarkan kernel Linux yang dimodifikasi. Android menyediakan platform terbuka bagi para pengembang untuk menciptakan aplikasi mereka sendiri untuk digunakan oleh bermacam piranti bergerak (Safaat, 2012).

\subsection{MIT App Inventor}

App Inventor adalah sebuah aplikasi web pemrograman visual open source yang digunakan untuk mengembangkan aplikasi mobile berbasis android dengan dukungan fitur drag and drop tool. Untuk mendesain sebuah user interface suatu aplikasi dapat dilakukan dengan menyusun komponen-komponen aplikasi menggunakan aplikasi web GUI builder. Selanjutnya behavior dari komponen-komponen tersebut didefinisikan menggunakan sederetan blok instruksi yang cara menggunakannya seperti puzzle.
App Inventor menggunakan Kawa Language Framework dan Kawa's dialect yang dikembangkan oleh Per Brother. Kedua aplikasi tersebut didistribusikan sebagai bagian dari GNU operating system oleh Free Software Foundation. Kedua aplikasi tersebut dijadikan compiler dan menerjemahkan visual block programming untuk diimplementasikan pada platform android (Wolber, 2011).

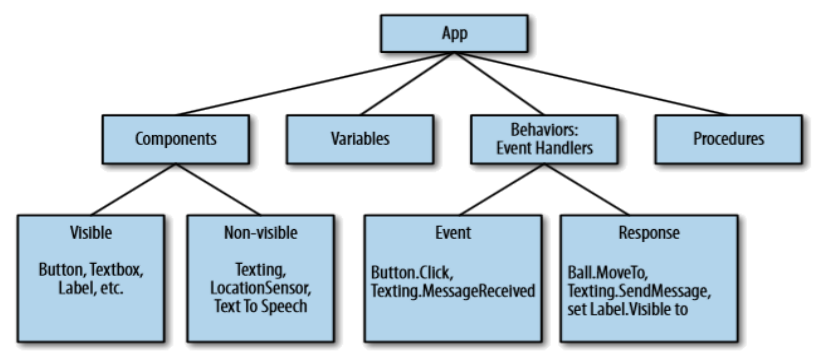

Gambar 1 Arsitektur Aplikasi MIT App Inventor

\subsection{Database System}

Pangkalan data atau basis data (bahasa Inggris: database), atau sering pula dieja basisdata, adalah kumpulan informasi yang disimpan di dalam komputer secara sistematik sehingga dapat diperiksa menggunakan suatu program komputer untuk memperoleh informasi dari basis data tersebut. Perangkat lunak yang digunakan untuk mengelola dan memanggil kueri (query) basis data disebut sistem manajemen basis data (database management system, DBMS).

Dalam lingkungan pemrograman menggunakan MIT App Inventor terdapat 2 (dua) cara yang dapat digunakan untuk menyimpan data/informasi yaitu menggunakan komponen variable dan komponen database. Variable digunakan untuk menyimpan data/informasi secara sementara, dimana data/informasi yang disimpan akan hilang ketika aplikasi ditutup. Sedangkan database digunakan untuk menyimpan data/informasi secara permanen. Terdapat 2 (dua) macam database dalam MIT App Inventor yaitu TinyDB dan TinyWebDB.

\subsection{Research and Development $(R \& D)$}

Penelitian ini bertujuan untuk merancang dan membuat sebuah sebuah sistem basis data dalam jaringan (online) untuk aplikasi kalkulasi biaya cetak buku yang dapat dijalankan pada perangkat bergerak dengan sistem operasi android. Oleh karena itu, jenis penelitian yang tepat adalah penelitian research and development (R\&D). Menurut Sugiyono (2009), Research and Development (R\&D) adalah metode penelitian yang digunakan untuk menghasilkan produk tertentu, dan menguji keefektifan produk tertentu. Produk tersebut dapat dihasilkan dengan menggunakan penelitian yang bersifat analisis terhadap kebutuhan.Pengujian terhadap efektifitas dari produk tesebut dilakukan agar dapat digunakan oleh masyarakat secara luas.

\section{KONSEP PERANCANGAN}

Untuk menghasilkan produk berupa perangkat lunak (software) aplikasi mobile platform android informasi peta pariwisata di Jakarta, maka pelaksanaan penelitian research and development (R\&D) ini harus mengikuti langkah-langkah baku dalam 
pembuatan perangkat lunak (software), antara lain sebagai berikut :

a. System Engineering (Rekayasa Sistem)

Perangkat lunak merupakan bagian dari sistem yang lebih besar, maka pekerjaan dimulai dari pengumpulan data agar dapat diketahui elemen- elemen yang hendak dialokasikan ke dalam perangkat lunak. Hal ini penting dilakukan ketika perangkat lunak harus berkomunikasi dengan pengguna (manusia), perangkat keras (hardware), dan basis data. Rekayasa sistem dan analisis menekankan pada pengumpulan kebutuhan pada level sistem dengan sedikit perancangan dan analisis.

b. System Analysis (Analisis Sistem)

Pada tahap ini dilakukan analisa pemecahaan permasalahan dari data dan informasi yang telah didapatkan dari tahap penelitian yang sebelumnya, serta mengumpulkan kebutuhan-kebutuhan sistem basis data dalam jaringan (online) untuk aplikasi kalkulasi biaya cetak buku yang dapat digunakan pada perangkat mobile device dengan sistem operasi Android yang akan dibangun.

c. Design (Perancangan Sistem)

Ada 4 atribut untuk desain yaitu struktur data, arsitektur sistem, sistem prosedur dan tampilan antar muka. Proses desain mengubah kebutuhan- kebutuhan menjadi bentuk karakteristik yang dimengerti perangkat lunak sebelum dimulai penulisan program. Desain ini harus didokumentasi dengan baik dan menjadi konfigurasi perangkat lunak sistem basis data dalam jaringan (online) untuk aplikasi kalkulasi biaya cetak buku yang dapat digunakan pada perangkat mobile device dengan sistem operasi Android yang akan dibangun..

d. Coding (Pengkodean)

Setelah tahap perancangan (design) kemudian dilanjutkan dengan menerjemahkan desain yang telah dibuat menjadi bentuk yang dapat mengerti oleh komputer. Pada tahap ini digunakan MIT App Inventor sebagai sebuah IDE (Integrated Development Environment) untuk mengembangkan perangkat lunak sistem basis data dalam jaringan (online) untuk aplikasi kalkulasi biaya cetak buku yang dapat digunakan pada perangkat mobile device dengan sistem operasi Android yang akan dibangun..

e. Testing (Pengujian)

Setelah tahap pengkodean program telah dilakukan dan program dapat berjalan, maka tahap selanjutnya adalah tahap pengujian program. Pengujian memfokuskan pada logika internal dari perangkat lunak, fungsi eksternal dan mencari segala kemungkinan masalah selanjutnya memeriksa apakah perangkat lunak sistem basis data dalam jaringan (online) untuk aplikasi kalkulasi biaya cetak buku pada perangkat mobile device dengan sistem operasi Android yang dibangun tersebut telah sesuai dengan yang diharapkan.

f. Maintenance (Perawatan)

Pada tahap ini dilakukan perawatan terhadap perangkat lunak sistem basis data dalam jaringan (online) untuk aplikasi kalkulasi biaya cetak buku pada perangkat mobile device dengan sistem operasi Android yang sudah jadi. Dalam penggunaannya akan masih terdapat potensi ditemukannya kesalahan (error) atau ada fitur baru yang perlu ditambahkan, sehingga perlu dilakukan pemeliharaan.

\section{HASIL DAN PEMBAHASAN}

\subsection{Perancangan Aplikasi}

Pelaksanaan penelitian diawali dengan tahap merancang sebuah sistem basis data dalam jaringan (online database) yang digunakan untuk menyimpan data harga dan tarif komponen biaya cetak secara terpusat. Online database tersebut membuat setiap aplikasi kalkulasi biaya cetak yang telah terinstal pada perangkat bergerak (mobile) android dapat melakukan perhitungan menggunakan data harga dan tarif yang selalu disesuaikan dengan kondisi pasar setiap saat.

Dengan demikian sistem yang akan dibangun pada penelitian ini terdiri dari sistem online database untuk menyimpan data harga dan tarif, aplikasi mobile untuk memutakhirkan data harga dan tarif, dan aplikasi mobile untuk melakukan perhitungan estimasi biaya pekerjaan cetak. Gambar 2 menunjukkan desain sistem online database yang akan dibangun.

\subsection{Proses Pembuatan}

Sistem online database yang dibuat menggunakan layanan dari Google Cloud Platform. Program kustomisasi tinywebdb (online database) yang disediakan oleh MIT App Inventor ditulis dalam bahasa Phyton sehingga dibutuhkan instalasi Phyton yang dapat diunduh dari https://www.phyton.org dan Google App Engine SDK for Phyton dari https://cloud.google.com/appengine. Aplikasi online database yang dijalankan oleh server Google App Engine menggunakan URL: https://kbc-onlinedatabase.appspot.com/. Pada gambar 3 diperlihatkan tampilan online database yang telah berisi data harga dan tarif komponen biaya cetak.

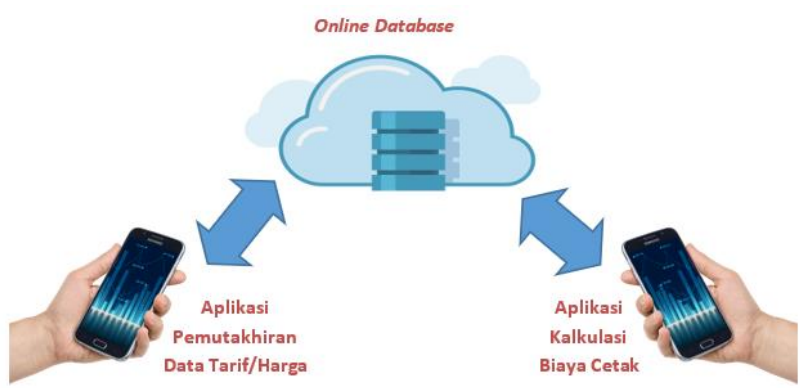

\section{Gambar 2 Desain Sistem Online Database untuk Aplikasi} Kalkulasi Biaya Cetak

\subsection{Hasil Pengujian}

Setelah proses pembuatan aplikasi dilaksanakan sesuai dengan perancangan sistem yang telah dibuat, tahap selanjutnya adalah pengujian sistem/aplikasi. Tahap pengujian pada penelitian ini dibagi menjadi 2 (dua) bagian yaitu tahap pengujian run-time yang merupakan pengujian sistem/aplikasi yang dibuat apakah telah sesuai dengan hasil rancangan sistem/aplikasi yang telah dibuat sebelumnya, dan berikutnya adalah pengujian perhitungan yang merupakan pengujian keakuratan hasil perhitungan dibandingkan dengan perhitungan yang dilakukan secara manual. Hasil pengujian run-time untuk aplikasi pemutakhiran data tarif/harga komponen biaya cetak dapat dilihat pada gambar 4 
sampai dengan 9, sedangkan untuk aplikasi kalkulasi biaya cetak dapat dilihat pada gambar 10 sampai dengan 16.

Pada pengujian perhitungan dilakukan perbandingan hasil perhitungan menggunakan aplikasi kalkulasi biaya cetak terhadap hasil perhitungan manual dengan contoh pekerjaan cetak buku dengan spesifikasi tertentu. Adapun spesifikasi pekerjaan cetak buku yang digunakan adalah sebagai berikut:

1. Ukuran Buku: A5 $(14,8 \mathrm{~cm} \mathrm{x} 21 \mathrm{~cm})$

2. Jumlah Halaman: 84 halaman ( 80 halaman isi dan 4 halaman kulit)

3. Warna Isi: 1 warna

4. Warna Kulit: 4 warna

5. Kertas Isi: HVO 80 gram

6. Kertas Kulit: Art Carton 180 gram

7. Jenis Penjilidan: Jahit Kawat

8. Oplah Cetak: 10000 eksemplar

9. Ukuran Mesin Cetak : Plano $(65 \mathrm{~cm} \times 100 \mathrm{~cm})$

10. Inschiet Isi :5\%

11. Inschiet Kulit: $20 \%$

12. Prosentase Profit: $10 \%$

13. Prosentase Pajak: $11,5 \%$

\subsection{Analisa dan Pembahasan}

Pada tahap pengujian run-time aplikasi, proses pengujian dilakukan dengan menggunakan Smartphone Andromax ES (C46B2G), processor Snapdragon 410 Quad Core 1,20 GHz, Cortex A-53, Memory 1 Giga Byte RAM, Internal Storage 8 Giga Byte, Display 4 inch LCD, WVGA (480 x 800 piksel), dan Operating System Android 5 Lollipop.

Pada saat membuka halaman Daftar Harga/Tarif, baik pada aplikasi Pemutakhiran Data Harga/Tarif seperti yang terlihat pada gambar 5 maupun aplikasi Kalkulasi Biaya Cetak seperti yang terlihat pada gambar 11 dibutuhkan waktu lebih kurang 5 detik untuk menampilkan semua nominal harga dan tarif secara keseluruhan. Hal ini dapat terjadi dikarenakan data harga dan tarif tidak disimpan pada database aplikasi yang berada pada perangkat melainkan disimpan pada online database.

Dengan demikian waktu jeda yang terjadi adalah waktu yang dibutuhkan untuk proses komunikasi data pada jaringan internet dimana semakin besar bandwidth kecepatan internet yang dimiliki oleh pengguna maka akan mempersingkat waktu jeda yang terjadi.

Hasil pengujian perhitungan terhadap pekerjaan cetak buku yaitu Harga per halaman dari hasil perhitungan manual adalah $\mathrm{Rp}$ 30,88,- sedangkan dari hasil perhitungan menggunakan aplikasi adalah Rp 31,-. Perbedaan hasil perhitungan tersebut dapat disajikan dalam bentuk prosentase kesalahan (\% Error). Perhitungan prosentase kesalahan (\% Error) dapat dilakukan dengan menggunakan rumus :

$\%$ Error $=$ (hasil perhitungan aplikasi - hasil perhitungan manual)/(hasil perhitungan manual) $\times 100 \%$

Dengan demikian didapatkan perhitungan sebagai berikut :

$\%$ Error $=[(31-30,88) / 30,88] \times 100 \%$

$$
\begin{aligned}
& =0,3886 \% \\
& \approx 0,4 \%
\end{aligned}
$$

Hal ini menunjukan bahwa perhitungan menggunakan aplikasi masih memiliki tingkat akurasi hasil perhitungan yang cukup tinggi yaitu $99,6 \%(100 \%-0,4 \%)$. Adapun penyebab terjadinya perbedaan hasil perhitungan manual dengan aplikasi dapat dimungkinkan karena pada saat proses perhitungan terjadi perbedaan mekanisme pembulatan angka desimal di belakang koma yang berbeda.

\section{App Inventor (TinyWebDB) Web Database Service}

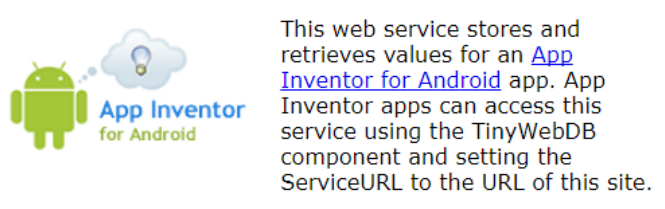

Search database for a tag

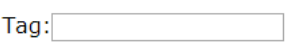

Get value

Returned as value to TinyWebDB component:

Store a tag-value pair in the databse

Tag: $\square$

Value: $\square$

\begin{tabular}{|c|c|c|c|}
\hline Key & Value & Created (GMT) & \\
\hline tarif_desain_A4 & "600000" & $\begin{array}{l}\text { Nov. 28, 2016, 5:06 } \\
\text { p.m. }\end{array}$ & \\
\hline tarif_desain_A5 & "300000" & $\begin{array}{l}\text { Aug. 18, 2016, 7:09 } \\
\text { p.m. }\end{array}$ & $\sqrt{\mathrm{De}}$ \\
\hline tarif_mengepak & 6500 & $\begin{array}{l}\text { June } 30,2016,7: 22 \\
\text { p.m. }\end{array}$ & Delete \\
\hline tarif_mengepak & "6501" & $\begin{array}{l}\text { June } 30,2016,7: 22 \\
\text { p.m. }\end{array}$ & Delete \\
\hline tarif_memotong & 350 & $\begin{array}{l}\text { June } 30,2016,4: 05 \\
\text { p.m. }\end{array}$ & Delete \\
\hline tarif_penjilidan & 2.34 & $\begin{array}{l}\text { June } 30,2016,4: 05 \\
\text { p.m. }\end{array}$ & Delete \\
\hline tarif_menjahit & 40 & $\begin{array}{l}\text { June } 30,2016,4: 04 \\
\text { p.m. }\end{array}$ & Delete \\
\hline tarif_mengomplit & 25 & $\begin{array}{l}\text { June } 30,2016,4: 03 \\
\text { p.m. }\end{array}$ & $\mathrm{De}$ \\
\hline tarif_melipat_16katern & 25 & $\begin{array}{l}\text { June } 30,2016,4: 03 \\
\text { p.m. }\end{array}$ & [ \\
\hline tarif_melipat_32katern & 50 & $\begin{array}{l}\text { June } 30,2016,4: 02 \\
\text { p.m. }\end{array}$ & Delete \\
\hline harga_AC_210 & 550000 & $\begin{array}{l}\text { June } 30,2016,4: 02 \\
\text { p.m. }\end{array}$ & Delete \\
\hline harga_AC_180 & 412500 & $\begin{array}{l}\text { June } 30,2016,4: 02 \\
\text { p.m. }\end{array}$ & Delete \\
\hline harga_HVO_70 & 165000 & $\begin{array}{l}\text { June } 30,2016,4: 01 \\
\text { p.m. }\end{array}$ & Delete \\
\hline harga_HVO_80 & 195000 & June $30,2016,4$ p.m. & Delete \\
\hline tarif_cetak_kulit & 25 & June 30, 2016, 4 p.m. & Delete \\
\hline tarif_cetak_isi & 57 & June $30,2016,4$ p.m. & Delete \\
\hline harga_pelat_cetak & 50000 & $\begin{array}{l}\text { June 30, 2016, 3:59 } \\
\text { p.m. }\end{array}$ & Delete \\
\hline tarif_montase & 17500 & $\begin{array}{l}\text { June 30, 2016, 3:59 } \\
\text { p.m. }\end{array}$ & Delete \\
\hline tarif_film_separasi & 350 & $\begin{array}{l}\text { June } 30,2016,3: 58 \\
\text { p.m. }\end{array}$ & Delete \\
\hline tarif_film_negatif & 30 & $\begin{array}{l}\text { June 30, 2016, 3:58 } \\
\text { p.m. }\end{array}$ & Delete \\
\hline tarif_setting_A5 & 6000 & $\begin{array}{l}\text { June 30, 2016, 3:57 } \\
\text { p.m. }\end{array}$ & Delete \\
\hline tarif_setting_A4 & 9000 & $\begin{array}{l}\text { June 30, 2016, 3:57 } \\
\text { p.m. }\end{array}$ & Delete \\
\hline
\end{tabular}

Store a value

Gambar 3 Tampilan dari online database (URL: https://kbc-online-database.appspot.com) 


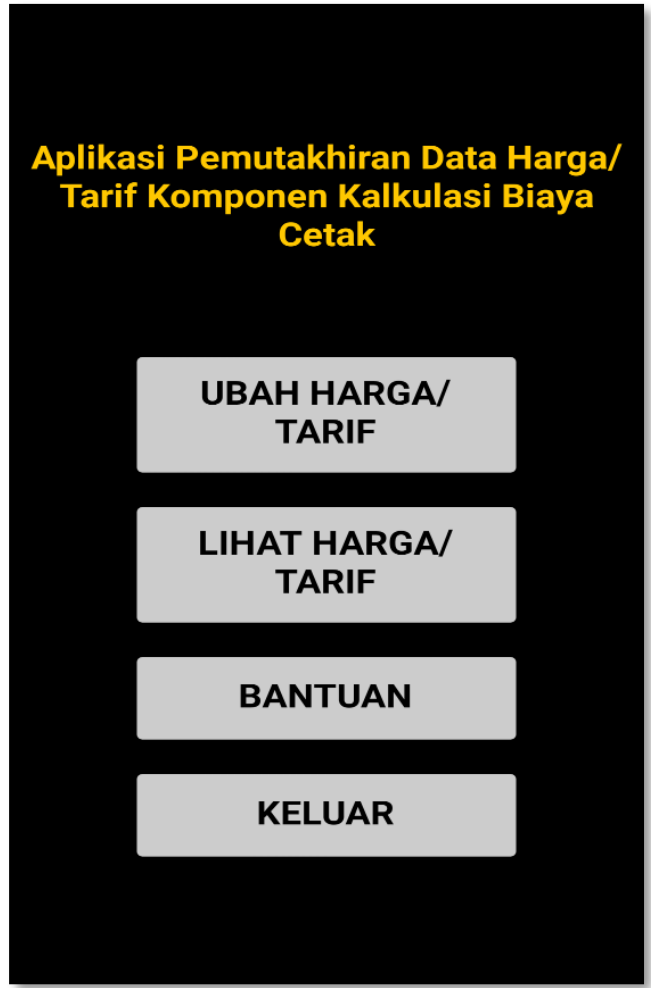

Gambar 4 Hasil Pengujian run-time Aplikasi Pemutakhiran Data: halaman utama

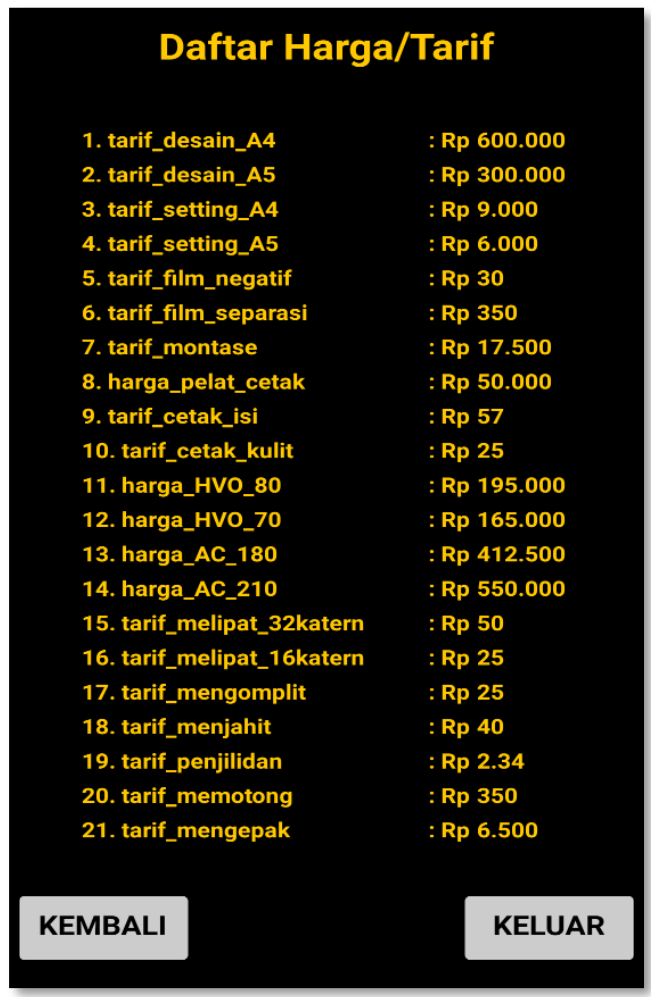

Gambar 5 Hasil Pengujian run-time Aplikasi Pemutakhiran Data: halaman Daftar Harga/Tarif

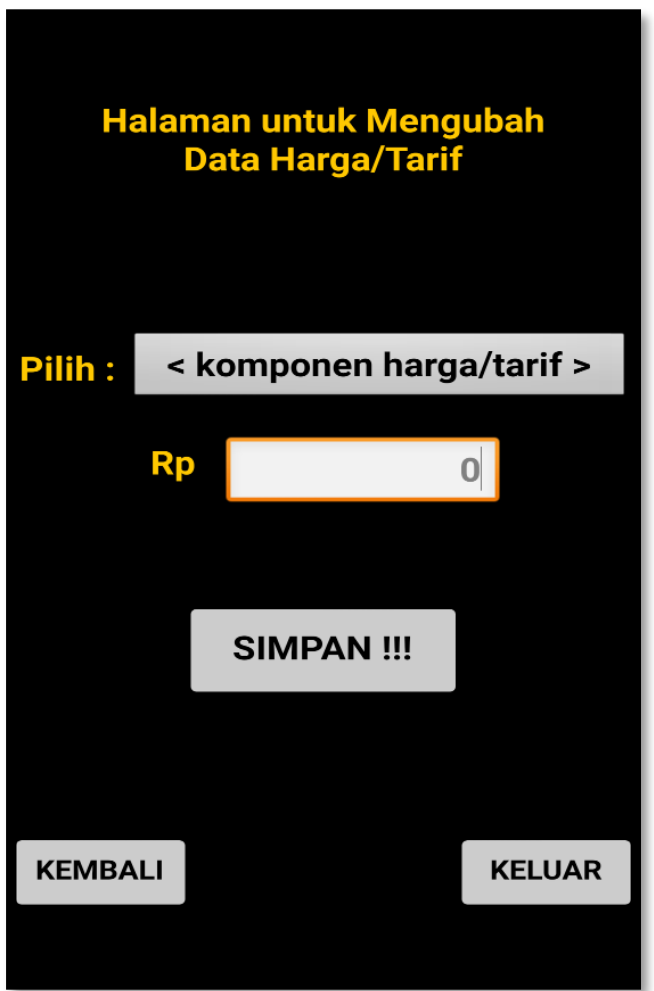

Gambar 6 Hasil Pengujian run-time Aplikasi Pemutakhiran Data: halaman untuk mengubah data harga/tarif kondisi belum dipilih

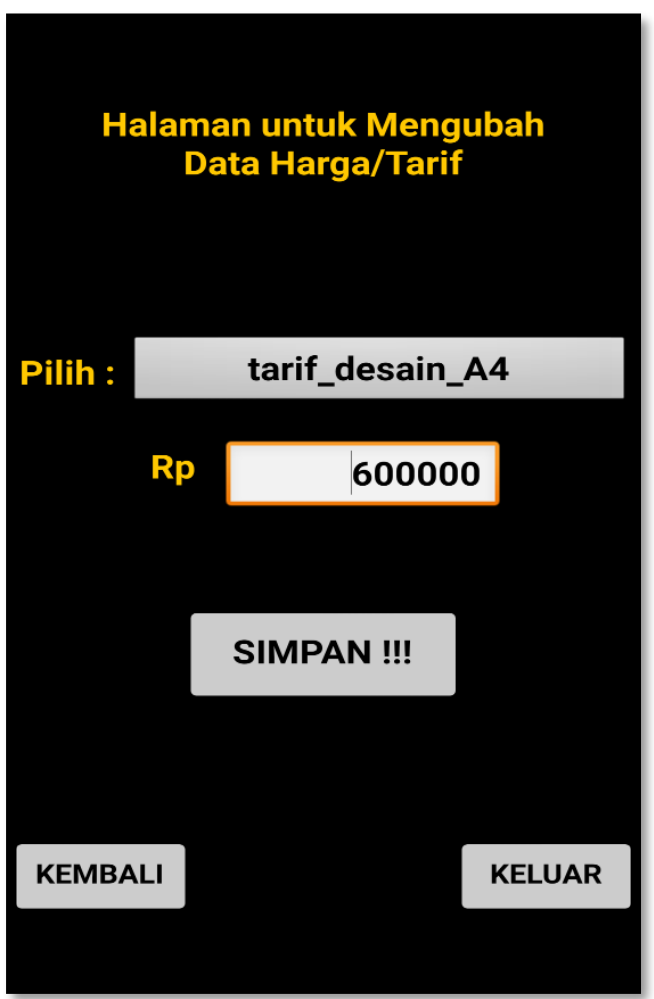

Gambar 7 Hasil Pengujian run-time Aplikasi Pemutakhiran Data: halaman untuk mengubah data harga/tarif kondisi telah dipilih 


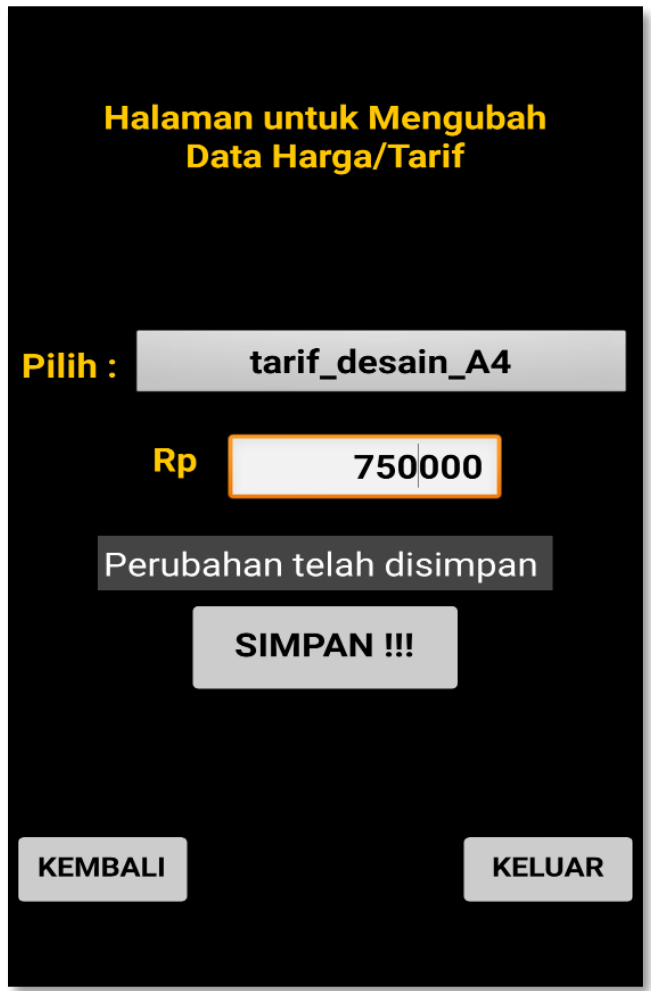

Gambar 8 Hasil Pengujian run-time Aplikasi Pemutakhiran Data: halaman untuk mengubah data harga/tarif kondisi telah diubah

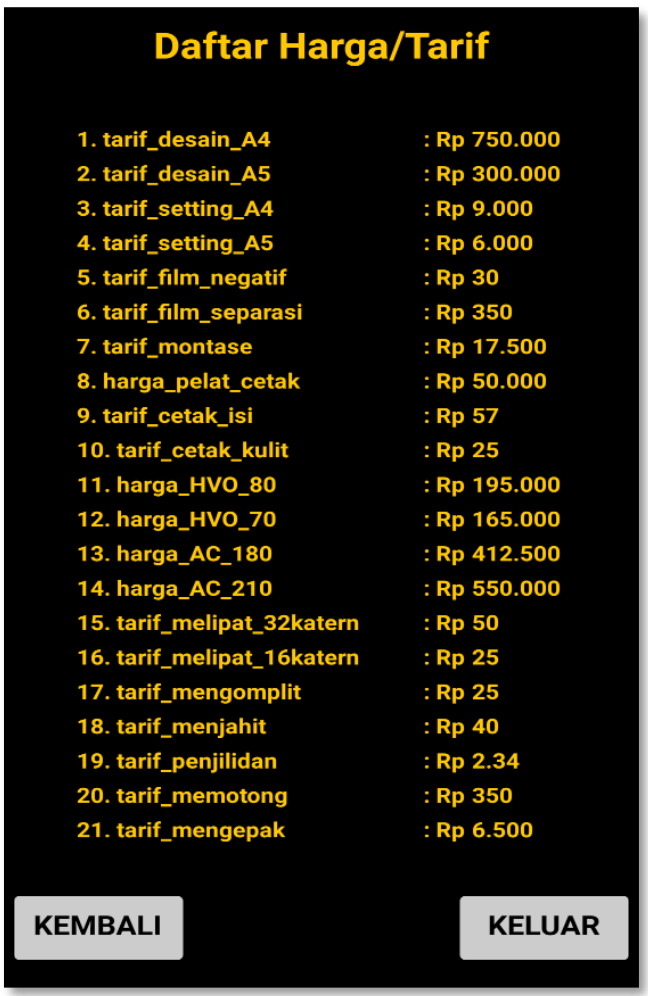

Gambar 9 Hasil Pengujian run-time Aplikasi Pemutakhiran Data: halaman Daftar Harga/Tarif kondisi telah diubah

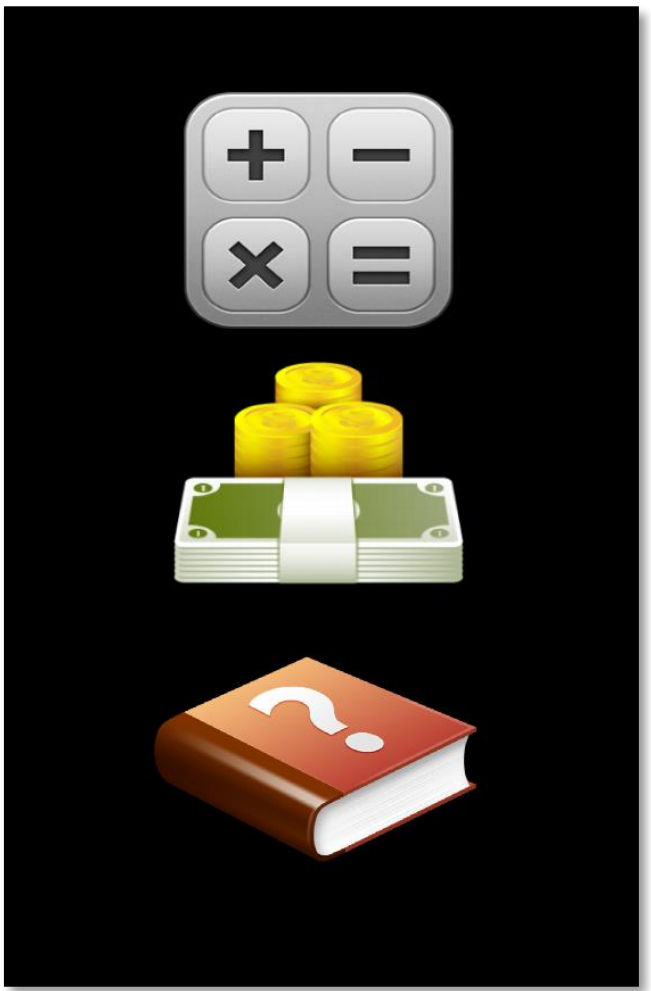

Gambar 10 Hasil Pengujian run-time Aplikasi Kalkulasi Biaya Cetak: halaman utama

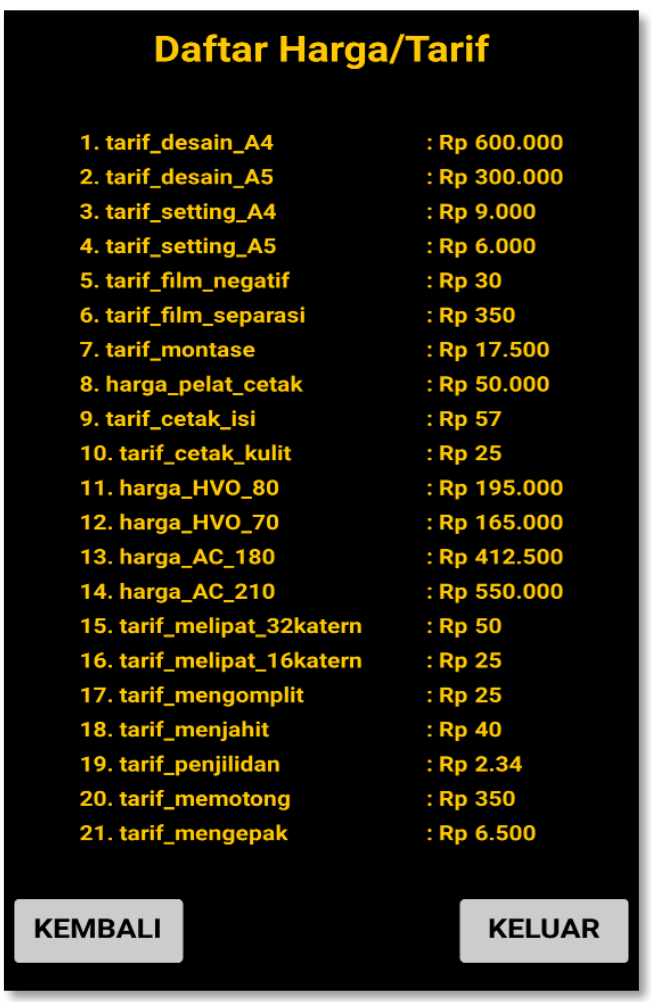

Gambar 11 Hasil Pengujian run-time Aplikasi Kalkulasi Biaya Cetak: halaman Daftar Harga/Tarif 


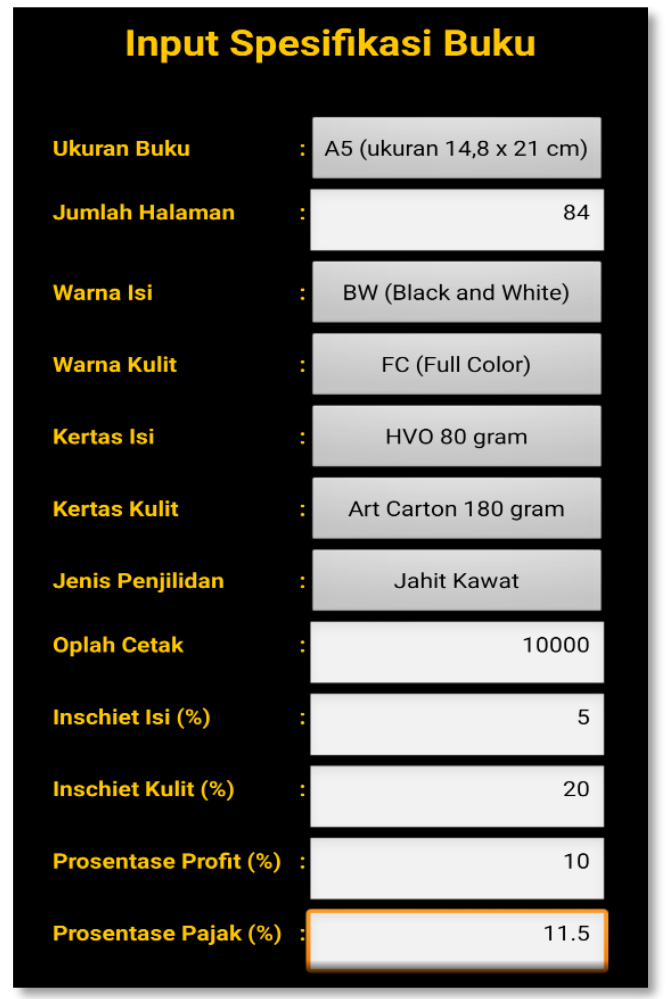

Gambar 12 Hasil Pengujian run-time Aplikasi Kalkulasi Biaya Cetak: halaman Input Spesifikasi Buku kondisi telah di-input

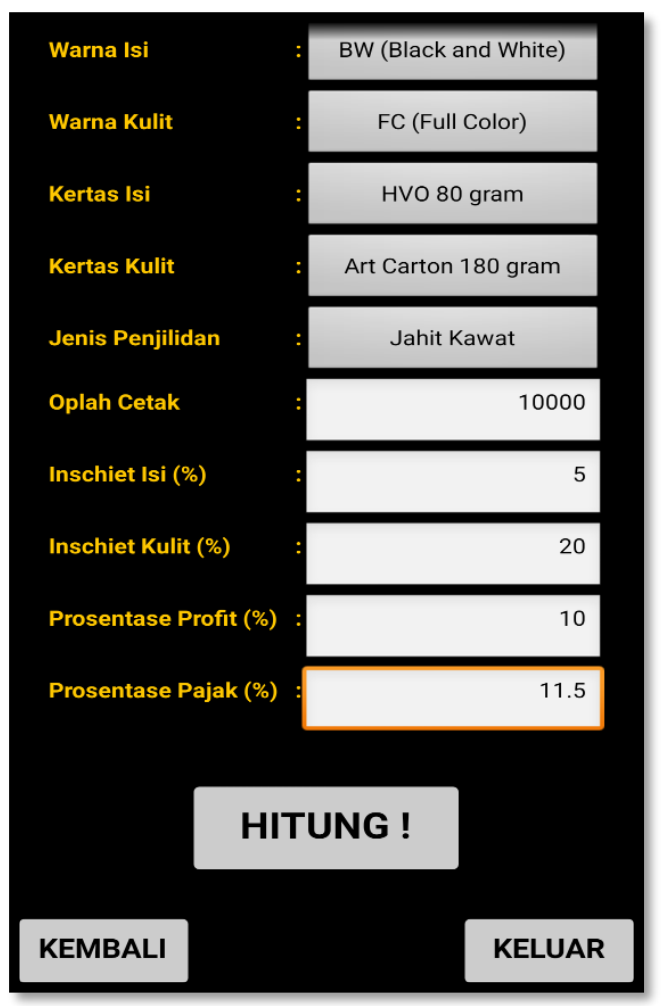

Gambar 13 Hasil Pengujian run-time Aplikasi Kalkulasi Biaya Cetak: halaman Input Spesifikasi Buku kondisi telah di-input (lanjutan)

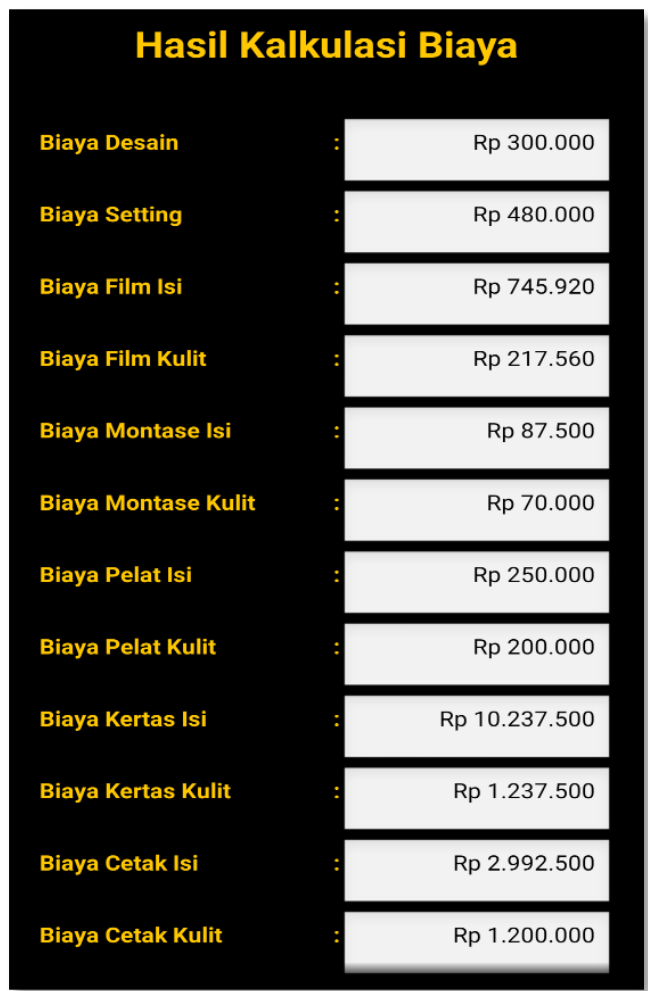

Gambar 14 Hasil Pengujian run-time Aplikasi Kalkulasi Biaya Cetak: halaman Hasil Kalkulasi Biaya

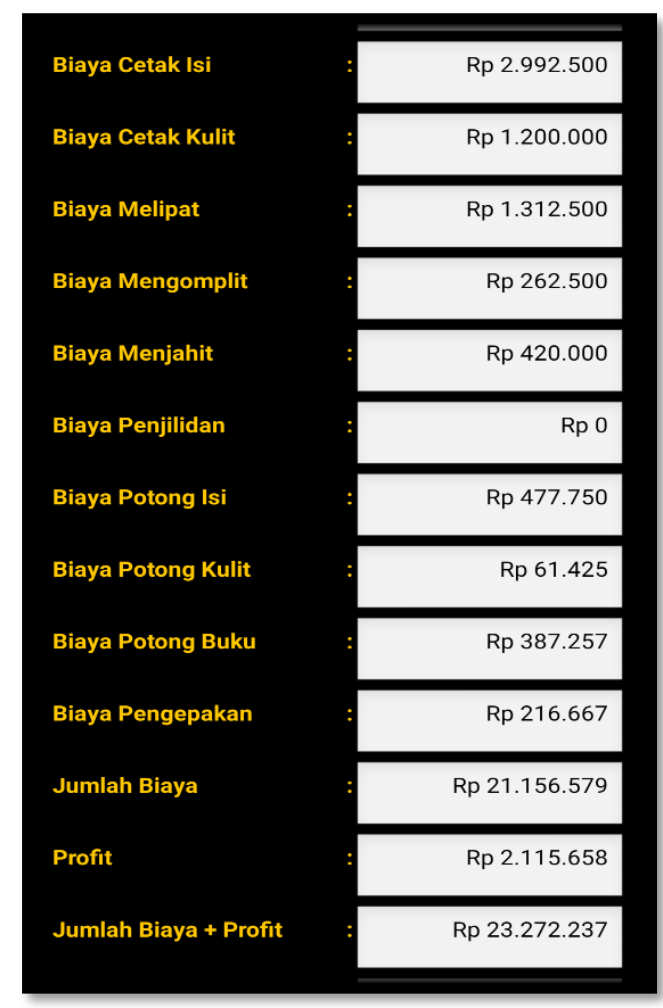

Gambar 15 Hasil Pengujian run-time Aplikasi Kalkulasi Biaya Cetak: halaman Hasil Kalkulasi Biaya (lanjutan) 


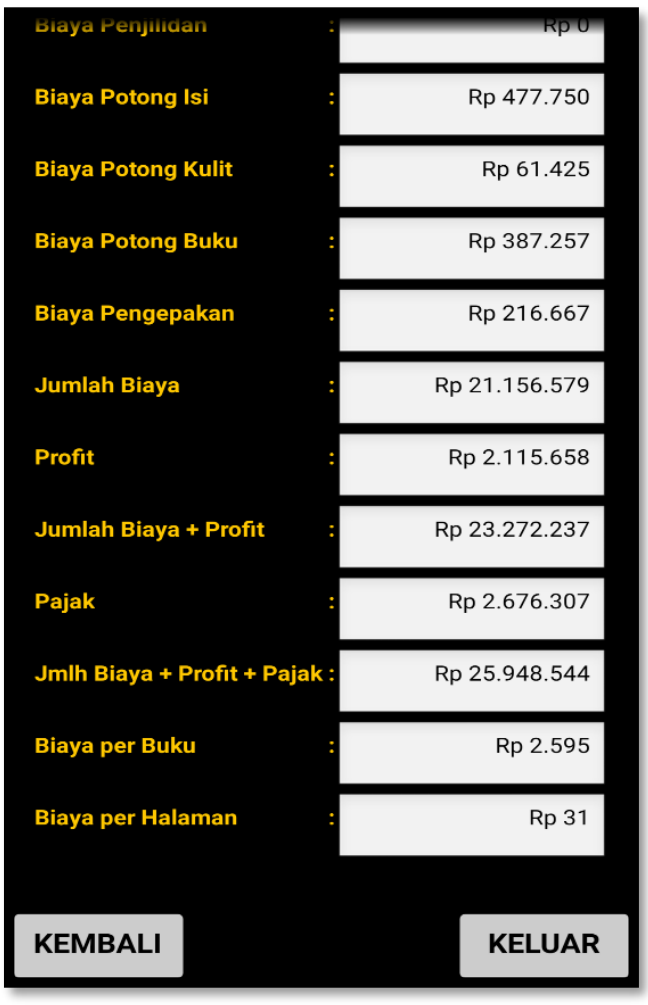

Gambar 16 Hasil Pengujian run-time Aplikasi Kalkulasi Biaya Cetak: halaman Hasil Kalkulasi Biaya (lanjutan)

\section{KESIMPULAN DAN SARAN}

\subsection{Kesimpulan}

Pada saat pengujian run-time yaitu saat membuka halaman Daftar Harga/Tarif, baik pada aplikasi Pemutakhiran Data Harga/Tarif maupun aplikasi Kalkulasi Biaya Cetak dibutuhkan waktu lebih kurang 5 detik untuk menampilkan semua nominal harga dan tarif secara keseluruhan. Hal ini dapat terjadi dikarenakan data harga dan tarif disimpan pada online database. Waktu jeda yang terjadi adalah waktu yang dibutuhkan untuk proses komunikasi data pada jaringan internet.

Hasil pengujian perhitungan menunjukkan adanya perbedaan antara hasil perhitungan manual dan hasil perhitungan aplikasi. Prosentase kesalahannya adalah $0,4 \%$, dengan demikian tingkat akurasi perhitungan menggunakan aplikasi masih cukup tinggi yaitu 99,6\%. Adapun perbedaan ini terjadi karena adanya perbedaan mekanisme pembulatan angka desimal di belakang koma pada masing-masing perhitungan.

\subsection{Saran}

Terdapat beberapa saran pengembangan agar aplikasi ini dapat ditingkatkan efektifitasnya sehingga dapat bermanfaat bagi lebih banyak khalayak antara lain:

1. Penambahan jenis pilihan pada variable input disesuaikan dengan kondisi ril di lapangan, sehingga dapat meningkatkan efektifitas penggunaan aplikasi untuk lebih banyak spesifikasi pekerjaan cetak.

2. Pengembangan aplikasi kalkulasi biaya cetak dengan online database ini pada mainstream mobile platform lainnya (cross platform), seperti iOS, Windows Mobile, dan Blackberry, sehingga aplikasi ini dapat digunakan oleh lebih banyak pengguna.

\section{DAFTAR PUSTAKA}

[1.]Fling, Brian. 2009. Mobile Design and Development. O'Reilly Media.

[2.] Nofiandri, Sutiyo. 2015. Rancang Bangun Aplikasi Kalkulasi Biaya Cetak Pada Mobile Platform Berbasis Android. Jurnal Kreator Volume 02 Nomor 02.

[3.] Safaat, Nazarudin. 2011. Pemrograman Aplikasi Mobile Smartphone dan Tablet PC Berbasis Android. Penerbit Informatika. Bandung.

[4.] Sugiyono. 2008. Metode Penelitian Kunatitatif Kualitatif dan Research \& Development. Alfabeta.Bandung.

[5.]Tantra, Rudi. 2012. Manajemen Proyek Sistem Informasi. Penerbit Andi. Yogyakarta.

[6.] Tim Indonesia Design Power. 2008. Pengembangan Ekonomi Kreatif Indonesia 2025. Departemen Perdagangan Republik Indonesia. Jakarta.

[7.] Wahana Komputer. 2013. Pemrograman Android dengan App Inventor. Penerbit Andi. Yogyakarta.

[8.] Wolber, David and Abelson, Hal. 2011. App Inventor: Create Your Own Android Apps. O'Reilly Media.

\section{BIODATA PENULIS}

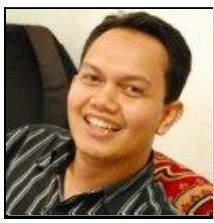

Nofiandri Setyasmara

Dosen pada Jurusan Desain Grafis, Politeknik Negeri Media Kreatif 